\title{
Advances in low cost marine technologies
}

\author{
M. Marcelli ${ }^{1}$, V. Piermattei ${ }^{1}$ \& G. Zappalà ${ }^{1,2}$ \\ ${ }^{I}$ DECOS Experimental Oceanology and Marine Ecology Laboratory, \\ Tuscia University, Viterbo, Italy \\ ${ }^{2}$ Istituto per l'Ambiente Marino Costiero (IAMC), \\ National Research Council, Messina, Italy
}

\begin{abstract}
In order to realize prevention and ecological risk analysis systems, the world environmental policy (UNEP, IMO, etc) is implementing complex decision systems based on economically sustainable activities including forecasting models, satellite images and sustainable observatory networks.

The oceanographic measurement networks play a key role both for satellite data calibration and mathematical models validation and feeding as well as to support the early warning systems for environmental pollution control and prevention.

The high costs of offshore mooring systems and traditional oceanographic cruises have suggested the use of VOS (Voluntary Observing Ships) to obtain affordable data.

Moreover, marine coastal areas can be monitored using small measure platforms integrating "on demand" the various measuring systems (meteorological stations, water samplers, automatic chemical analyzers, in situ and pumped oceanographic probes, etc).

For this purpose a big effort has been dedicated to the design, development and realization of new oceanographic devices.

This paper shows the advances in new technological devices: the TFLAP (Temperature Fluorescence LAunchable Probe) and the Automatic Multiple Launcher for expendable probes, to be used by VOS in open seas, and a coastal buoy to be moored near Civitavecchia, as a starting point of integrated coastal monitoring networks.
\end{abstract}


The described devices proved to be a cost effective solution to the need of modularity, flexibility, real time observing systems.

Keywords: observatory network, ocean color, VOS program, ocean monitoring, TFLAP, multiple launcher, expendable probes.

\section{Introduction}

The focus of international policy for the seas and oceans is steadily increasing due to the growth of consciousness, in the collective mentality, of their importance to man and his activities.

In addition to the use of the sea and its resources, that are traditionally exploited by humanity, and in addition to the essential role that the oceans and phytoplankton play in the climate balance, we constantly add new and important roles, such as exploitation of renewable energy and marine conservation of biodiversity, conservation meant as a pool of organic molecules of pharmaceutical compounds for possible future interest for humanity.

The oceanography sets itself as a synthesis science that can uniquely address the complex physical, geochemical and biological processes occurring in the sea: "Oceanography personifies interdisciplinary science of the 'blue' planet, Earth," as reported by Dickey and Bidigare [1].

The operational oceanography has been engaged in the development of new acquisition, transmission and assimilation systems in order to have the widest possible coverage of real time information, reflecting the guidelines of the World Meteorological Organization (WMO) and of the Intergovernmental Oceanographic Commission (IOC).

Moreover, physical and biological processes of marine ecosystems have a high spatial and temporal variability, whose study is possible only through high resolution and synoptic observations that require the simultaneous use of different platforms. "Until satellite appears, in the early 1970s, oceanography had endured a long period of "undersampling", so that, the most profund effect of the satellite oceanography was that for the first time ocean processes were adequately sampled" as stated by Munk [2].

However, the satellites, the data assimilation of mathematical models and the compliance with the standards for coastal studies, require in situ data. More than for the physical variables, the biological ones have to be observed in situ as reported by Marcelli et al. [3].

The attention to the state of marine environments is growing worldwide and the assessment of their resources needs always innovative methodologies, in order to develop policies and environmental governance for the sustainable management of the marine ecosystems.

Environment monitoring systems and networks were, in the years, designed and presented by various authors, among which, Carof et al. [4], Grisard [5], Eriksen [6], Griffiths et al. [7], Irish et al. [8], Paul [9], Seim et al. [10], Zappalà et al. [11], Nittis et al. [12], Crisafi et al. [13], Zappalà et al. [14, 15]. 
The methodologies for an operational monitoring of the oceans integrate satellite observations, drifting devices, Voluntary Observing Ships (VOS) and moorings:

- Satellite observation has the highest spatial and temporal sinopticity, but is limited by a series of factors: the lack of the third dimension, the low resolution in the coastal areas, the necessity of in situ data for sensors calibration.

- Drifter systems can measure physical, chemical and biological parameters, but their capability is limited by costs and power supply.

- The use of VOS in Ships Of Opportunity Program (SOOP) allows us to reduce operative costs of sea research, without affecting quality and increasing the spatial and temporal sinopticity of information.

- Mooring systems allow to collect a huge amount of data in near realtime for long-term monitoring.

At now, the main issue is to develop integrated measurement methods aimed at measuring physical and biological variables, integrating various networking, while simultaneously to develop new automated and low cost tools, primarily for the measurement of biological and chemical variables.

\section{Materials and methods}

Scientific activities were performed on two main lines: VOS equipments and moorings.

\subsection{VOS systems}

A Ships Of Opportunity Program (SOOP) was established in the Mediterranean Sea in September 1999, on behalf of the EC funded project Mediterranean Forecasting System - Pilot Project (MFS-PP), as described by Pinardi et al. [16].

The program is now evolving into a full Volunteer Observing Ships (VOS) system providing sea-temperature profiles and meteorological data.

The VOS, usually cargoes or ferries, allow us to repeat the same tracks, collecting data with a cyclic pattern.

The VOS program is based on the use of expendable probes, originally conceived for the Navy submarine warfare and later adopted by scientific community for oceanographic purposes.

The first expendable probe was the XBT (Expendable Bathy Thermograph), which was followed by XCTD (Expendable Conductivity, Temperature, and Depth profiling system) and ESV (Expendable Sound Velocimeter).

All of these probes are based on a consolidated technology: the probes can be released using manual or automatic launchers.

The depth reached by the XBT probes is estimated using a formula of the kind:

$$
\mathrm{Z}(\mathrm{t})=\mathrm{At}-\mathrm{Bt}^{2}
$$

where $\mathrm{Z}(\mathrm{t})$ is the depth, $\mathrm{t}$ the time and $\mathrm{A}$ and $\mathrm{B}$ probe related coefficients. 
The traditional commercial expendable probes are limited to the measurement of physical parameters, while also the biological ones are very important.

In this contest the TFLAP (Temperature Fluorescence LAunchable Probe), as described by Marcelli et al. [17, 18], was developed to fill this gap, ensuring both the quality of the measure and cost effectiveness.

TFLAP is an expendable probe which was developed for VOS purpose, launchable, like the others, from a moving ship. It measures pressure, temperature and fluorescence of chlorophyll $a$ along the water column.

Unlike the traditional XBT probe, incorporating only the temperature sensor and having no electronics on board, the TFLAP contains a modular electronic system to manage the different measure channels. Commercial low cost components were selected and tested for the realization of the first prototypes.

The probe (Fig. 1) is built around a central tube made in anticorodal (an aluminium alloy) in which a measurement cell is obtained, hosting the sensors immersed in the water flow. An outer tube, coaxial with the first, is used to obtain a pressure case for the system electronics.

A zinc ogive is used to make the probe heavy enough to sink at a predefined rate, while a plastic tail (hosting the reel of electrical wire connecting the probe to the launching system) stabilizes its movement.

While the probe sinks, the wire dereels from the tail (lower) coil; in the meantime, the wire dereeling from the upper coil compensates the ship movement.
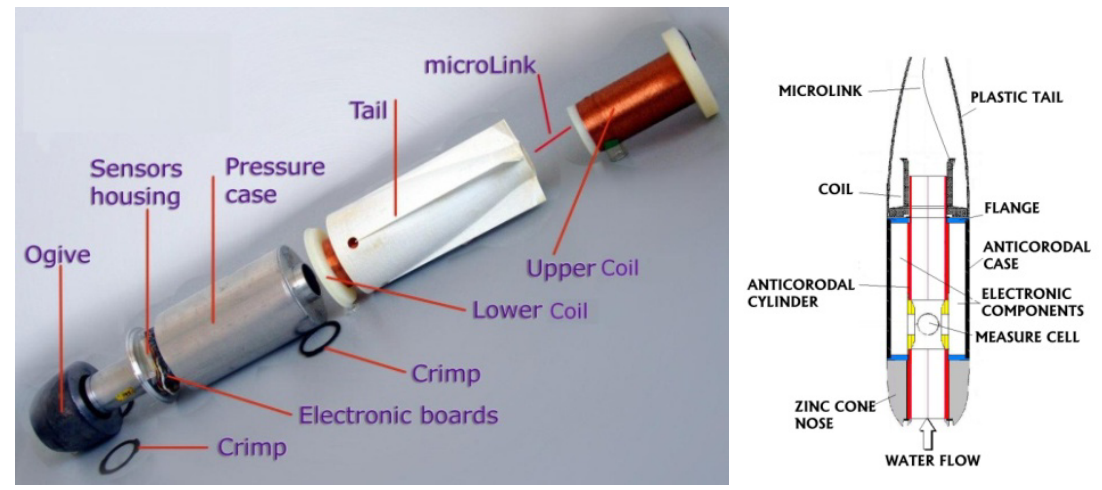

Figure 1: $\quad$ A partially assembled TFLAP and its section.

The measurement components include: a pressure transducer, a glass bulb temperature resistor for temperature measure; blue LEDs for fluorescence excitation, interferential filters and a photodiode for the fluorescence measure.

To better exploit the capabilities of TFLAP an enhanced version of the Automatic Multiple Launcher for expendable probes was set up.

The Multiple Launcher was designed in the Framework of MFS-TEP to enhance and automate the use of expendable probes from VOS. It has been described by Zappalà et al. [19], Zappalà and Manzella [20] and by Zappalà [21]. 
Originally designed to work with standard XBT probes, the system was enhanced to manage also TFLAPs, with a new serial interface and new communication and data display routines.

An example of Temperature and Fluorescence profiles measured using the TFLAP is shown in Fig. 2.

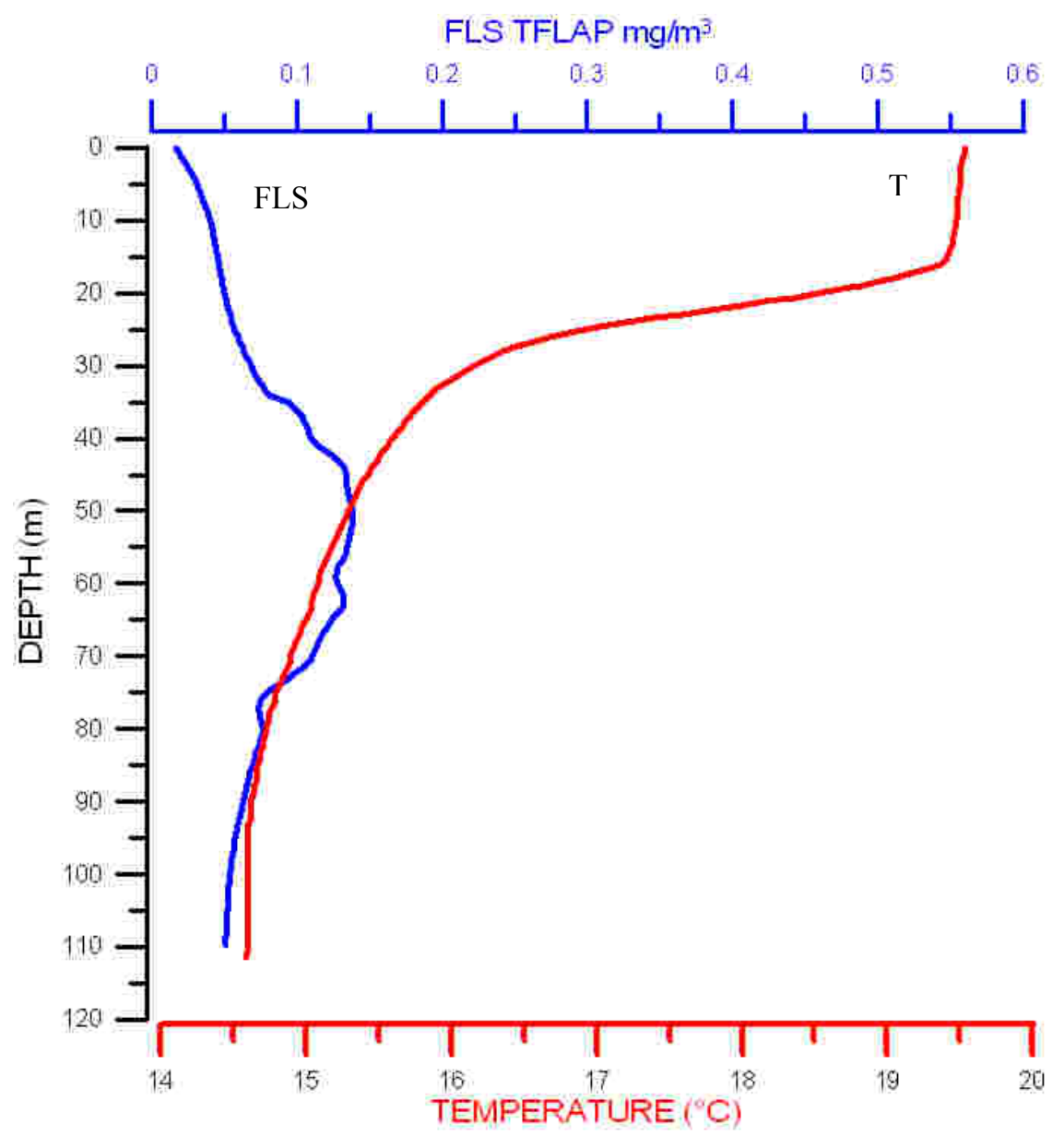

Figure 2: A plot of temperature and fluorescence profiles measured by the TFLAP.

\subsection{Moorings}

The buoy (or, more properly, the platform) was originally moored in Siracusa (Sicily) coastal waters as a part of a monitoring network funded by the Italian Ministry for University and Research, described by Zappalà et al. [22, 23]. 
Basically, it consisted in a $2 \mathrm{~m}$ x $4 \mathrm{~m}$ Orsogrill "floor", brought about $50 \mathrm{~cm}$ over the sea by ten horizontal axis cylindrical floaters distributed on the long sides; a semi-submersed chamber ("vessel") contained the measuring instruments, the batteries, the data acquisition and transmission and the pumping systems; an overhanging arc hosted meteorological sensors, the GSM antenna, the blinker and the radar reflector.

The power was given by four $12 \mathrm{~V} 50$ Ah accumulators recharged using four $50 \mathrm{~W}$ solar panels, used also to close and protect the semi-submersed chamber.

At present, the platform is undergoing a series of major modification and a complete instrumentation refitting to be used for a new monitoring program which is going to start in Civitavecchia waters.

The platform before the modification is shown in Fig. 3 (left); the modified version is presented in Fig. 3 (right).
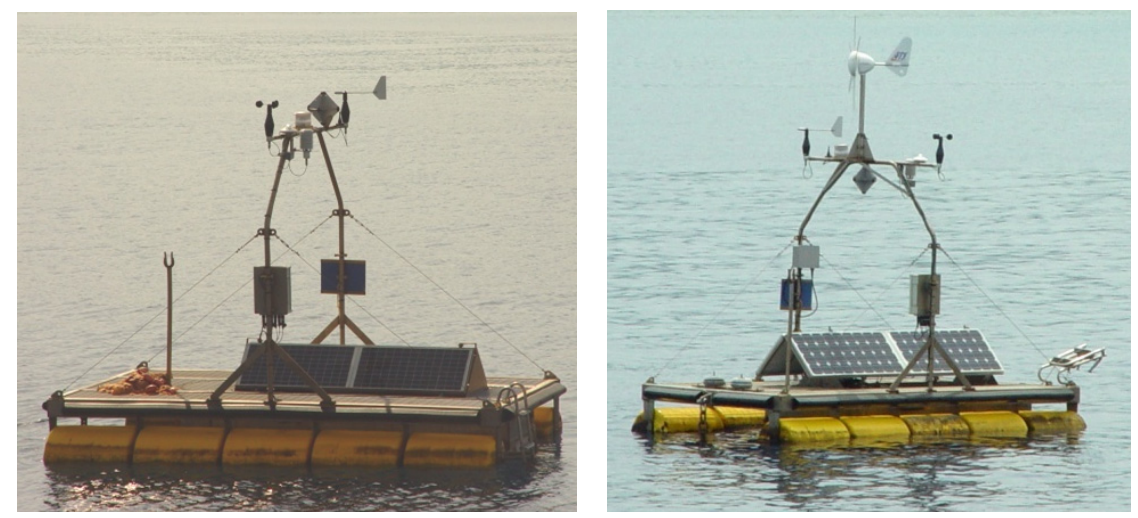

Figure 3: The platform before (left) and after (right) the modifications; it is evident the substitution of solar panels and the adding of the wind generator; being them totally submersed it is difficult to see the added floaters (two on each long side).

\subsubsection{The power supply}

To allow the use of more complex (and power consuming) instrumentation, taking into account possible problems with solar panels (long periods of bad weather, surface covering by oil film, damages caused by wave transported materials, etc.), the following improvements were made:

- a $200 \mathrm{~W}$ wind generator was added on the top the arc

- $\quad$ the $50 \mathrm{~W}$ panels were substituted with $80 \mathrm{~W}$ ones

- the power reserve was doubled adding four more accumulators.

Shunt or series voltage regulators, together with protecting diodes allow to properly recharge batteries, ensuring supply also in case of failure of one or more accumulators or generators.

The increase in weight has been balanced adding four auxiliary floaters that also, widening the submersed surface on short sides, enhance the buoy stability. 


\subsubsection{The data acquisition and transmission systems and the control software}

The data acquisition system uses PC/104 boards that implement a PC-like architecture; the technological developments obtained in the years made available new, more powerful electronic boards to substitute the Intel 386 used in the first buoy version and the Pentium family board adopted for the first version of the "automatic multiple launcher for expendable probes".

In the current standard version up to 12 serial ports are available to connect measuring instruments, switched on and off by solid state and electromechanical relays.

To monitor power system status (battery level, solar panels and wind generator voltage) a 16 single ended channels, 12 bit resolution Analog to Digital Converter (ADC) board is installed; it is also possible to add a 16 bit resolution $\mathrm{ADC}$ board to connect sensors with voltage or current output.

The original GSM modem has been substituted by a GSM-GPRS one, able (thanks to an embedded TCP-IP stack) to directly connect to Internet, to transfer data as e-mail messages, so allowing to de-localize the base station and to better disseminate acquired data.

A GPS receiver is included in the system to control its position: should the platform go out of the allowed area range, an "unmoored platform" alarm is sent to the base station and to selected cellular phones.

The system software is a new release of the original one, first described by Zappalà [24] and further expanding the enhancements reported by Zappalà [25].

It is coded partly in compiled BASIC and partly in Assembly in a DOS-like environment; remote control software is written in Visual Basic in Windows environment.

Basically, it consists in a "time machine" executing at pre-defined times sequences of macro-commands able to fully control the instruments and the data acquisition and transmission systems.

The sequences can be different for each time and are remotely reprogrammable without suspending system activity.

Acquired data are immediately stored in the local system disk (a solid state one), then formatted and sent via e-mail.

Being the messages sequentially numbered, it is easy for the receiving system to automatically detect a missing message and asking for its retransmission, simply sending an e-mail message or an SMS to the buoy.

\subsubsection{The pumping system}

The pumping system (shown during refitting operations in Fig. 4) uses a peristaltic pump to drive water from five depths to feed instruments (e.g. multiparametric probes, water samplers, colorimetric analyzers...) into a measurement chamber or in an open flow piping; after the measurements the system can be automatically washed with fresh water contained in a reservoir.

Of course, possible alterations of sample temperature and dissolved oxygen must be taken into account; no influence has been noticed on other parameters, 

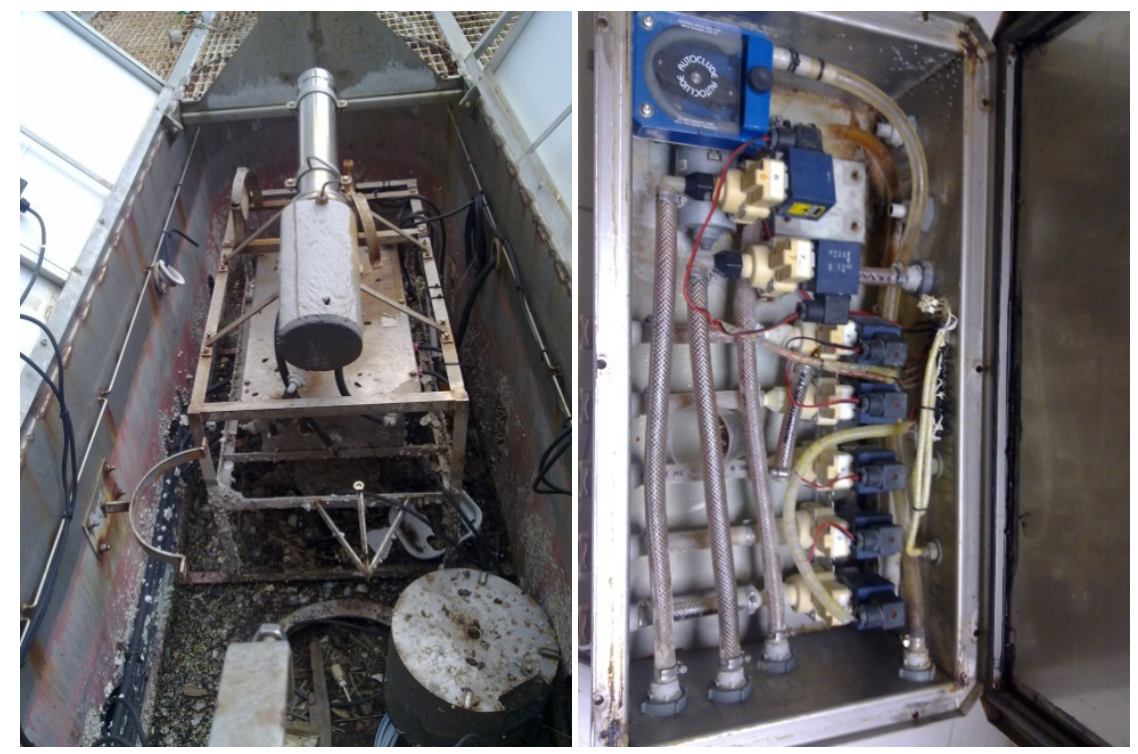

Figure 4: The water pumping system in the buoy (left) and on the bench (right) during refitting operations.

however, attention must be paid to avoid mixing in calculations in situ and pumped measured values (e.g. calculating salinity only using pumped samples).

\section{Discussion and conclusions}

The TFLAP probe was developed to overcome the lacking of measurements of fluorescence from chlorophyll $a$ in available expendable probes and to integrate the third dimension of satellite observation. The acquisition of a huge amount of data concerning chlorophyll $a$ estimation, together with temperature, allows the monitoring of marine productivity variation, giving important information to study the state of marine ecosystem.

Worth mentioning is the cost reduction that can be achieved by using the Automatic Multiple Launcher. One of the requirements in operational oceanography is the collection of data allowing the spatial resolution of mesoscale phenomena, which are of the order of 15-20 miles in the Mediterranean Sea.

Since ships are moving faster than 20 knots, the XBTs must be dropped every 20-30 min. Data collection along a section 400-500 miles long with a manual launcher requires the engagement of two-three technicians, having a cost of about 25 USD per hour. The total cost for personnel amounts to 1000-2000 USD for each trip. The cost of a multiple launcher is about 15000 USD, that can be recovered in 10-20 trips by engaging only one person. 
Coastal moorings not only offer a low-cost (or better not-too-high-cost) solution for environment monitoring, but also help integrate and calibrate data coming from satellite observations.

The devices here reported can be used for low cost operational oceanography monitoring and can be further implemented with other measuring systems (e.g. water sampler for off-line bacteriological, chemical and nutrient analyses, multispectral instruments, Acoustic Doppler Current Profiler).

Our group focused and is still working on the development of an integrated approach including: for the open waters, the development of low-cost tools and new sensors for the measurement of biological variables; for the coastal waters, the development of automatic measurement systems and their integration with the existing networks, with the ultimate goal of developing automated methods and low cost instruments, that, in a next future, will perform (near) real time biological and chemical measurements.

\section{References}

[1] Dickey, T. D. \& Bidigare, R. R., Interdisciplinary oceanographic observations: the wave of the future, Scientia Marina, 69(Suppl. 1), 23-42, 2005.

[2] Munk, W., Oceanography before, and after, the advent of satellites, Satellites, Oceanography and Society, edited by David Halpern, 9 Elsevier Science B.V., 2000.

[3] Marcelli, M., Di Maio, A., Donis, D., Mainardi, U. \& Manzella, G.M.R.. Development of a new expendable probe for the study of pelagic ecosystems from voluntary observing ships. Ocean Sci., 3, 1-10, 2007.

[4] Carof, A., H., Sauzade D. \& Henocque, Y., Arcbleu, an integrated surveillance system for chronic and accidental pollution. Proc. of OESIEEE OCEANS '94 Conference, III, pp. 298-302, 1994.

[5] Grisard, K., Eight years experience with the Elbe Estuary environmental survey net. Proc. of OES-IEEE OCEANS '94 Conference, I, pp. 38-43, 1994.

[6] Eriksen, C. C., Instrumentation for Physical Oceanography: the last two decades and beyond. NSF APROPOS Workshop - Ailomar, CA 15-17 December 1997.

[7] Griffiths, G., Davis, R., Eriksen, C., Frye, D., Marchand, P. \& Dickey, T., Towards new platform technology for sustained observations. Proc. of OceanObs 99, http:/www.bom.gov.au/OceanObs99/Papers/Griffiths.pdf

[8] Irish, J. D., Beardsley, R. C., Williams, W. J. \& Brink, K. H., Long-term moored observations on Georges Bank as part of the U. S. Globec Northwest Atlantic/Georges Bank program. Proc. of MTS-IEEE OCEANS '99 Conference, I, pp. 273-278, 1999.

[9] Paul, W., Buoy Technology. Marine Technology Society Journal, 35(2), pp. 54-57, 2001.

[10] Seim, H., Werner, F., Nelson, J., Jahnke, R., Mooers, C., Shay, L., Weisberg, R. \& Luther, M., SEA-COOS: Southeast Atlantic Coastal Ocean 
Observing System. Proc. of MTS-IEEE OCEANS 2002 Conference, I, pp. 547-555, 2002.

[11] Zappalà, G., Caruso, G. \& Crisafi, E., Design and use of advanced technology devices for sea water monitoring. Operational Oceanography. Implementation at the European and Regional Scales, eds. Flemming N. C., Vallerga S., Pinardi N., Behrens H.W.A., Manzella G., Prandle D., Stel J.H., Elsevier Oceanography Series, 66, 2002.

[12] Nittis, K., Tziavos, C., Thanos, I., Drakopoulos, P., Cardin, V., Gacic, M., Petihakis, G. \& Basana, R., The Mediterranean Moored Multi-sensor Array (M3A): system development and initial results. Annales Geophysicae, 21, pp. 75-87, 2003.

[13] Crisafi, E., Azzaro, F., Zappalà, G. \& Magazzù G., Integrated automatic systems for oceanographic research: some applications. Proc. of OES-IEEE OCEANS '94 Conference, I, pp. 455-460, 1994.

[14] Zappalà, G., Crisafi, E., Caruso, G., Azzaro, F. \& Magazzù, G., Coastal monitoring by an advanced technology platform. Proc. of Oceanology International 98 Conference Proceedings, I, pp. 69-84, 1998.

[15] Zappalà, G., Alberotanza, L. \& Crisafi, E., Assessment of environmental conditions using automatic monitoring systems. Proc. of MTS-IEEE OCEANS '99 Conference, II, pp. 796-800, 1999.

[16] Pinardi, N., Allen, I., Demirov, E., De Mey, P., Korres, G., Laskaratos, A., Le Traon, P., Y., Maillard, C., Manzella, G. \& Tziavos, C., The Mediterranean Ocean Forecasting System: first phase of implementation (1998-2001). Annales Geophysicae, 21, pp. 3-20, 2003.

[17] Marcelli, M., Di Maio, A., Piermattei, V., Zappalà, G. \& Manzella, G., Development of new technologies for the high variability phenomena data acquisition in the MFSTEP-VOS project. European Operational Oceanography: Present and Future, Proc. of the Fourth International Conference on EuroGOOS, eds. H. Dahlin, N.C. Flemming, P. Marchand, S. E. Petersson, pp. 184-187, 2006.

[18] Marcelli, M., Di Maio, A., Donis, D., Mainardi, U., \& Manzella, G., Development of a new expendable probe for the study of pelagic ecosystems from voluntary observing ships, Ocean Sci., 3, pp. 311-320, 2007. Online www.ocean-sci.net $/ 3 / 3 / 2007 /$

[19] Zappalà, G., Manzella G., An automatic multiple launcher for expendable probes. Proc. of the Fourth International Conference on EuroGOOS. Operational Oceanography: Present and Future, eds. H. Dahlin, N.C. Flemming, P. Marchand \& S. E. Petersson, European Commission Publication Office, pp. 188-191, 2006.

[20] Zappalà, G., Reseghetti, F. \& Manzella, G.M.R., Development of an automatic multiple launcher for expendable probes, Ocean Sci., 3, pp. 173178, 2007. Online www.ocean-sci.net/3/173/2007/

[21] Zappalà, G., Development of advanced instrumentation for operational oceanography. WIT Transactions on Modelling and Simulation, eds C. A. Brebbia \& G. M. Carlomagno, WIT Press, Southampton, 46, pp 841-850, 2007. 
[22] Zappalà, G., Caruso, G., \& Crisafi, E. The "SAM" integrated system for coastal monitoring. Proc. Of the 4th Int. Conf. On Environmental Problems in Coastal Regions, Coastal Environment IV, ed C.A. Brebbia, WIT Press: Southampton, pp. 341-350, 2002.

[23] Zappalà, G., Caruso, G., Azzaro, F., Crisafi, E. Integrated Environment Monitoring from Coastal Platforms. Proc. of the Sixth International Conference on the Mediterranean Coastal Environment, ed E. Ozhan, MEDCOAST, Middle East Technical University: Ankara, 3: pp 2007-1018, 2003.

[24] Zappalà, G., A software set for environment monitoring networks. Proc. of the Int. Conf. On Development and Application of Computer Techniques to Environmental Studies X. Envirosoft 2004, eds. G. Latini, G. Passerini, \& C. A. Brebbia, WIT Press, Southampton, pp. 3-12, 2004.

[25] Zappalà, G., A versatile software-hardware system for environmental data acquisition and transmission. WIT Transactions on Modelling and Simulation, eds C. A. Brebbia \& G. M. Carlomagno, WIT Press, Southampton, 48, pp 283-294, 2009. 